\title{
Cross-Section for Proton Transfer from a Large Peptide Ion to Ammonia in the Gas Phase
}

\author{
Stephen C. Davis \\ Kratos, Urmston, Manchester M61 2LD, UK \\ Peter J. Derrick \\ Warwick Institute of Mass Spectrometry and Department of Chemistry, University of Warwick, \\ Conventry CV4 7AL, UK \\ and Christoph Ottinger \\ Max-Planck-Institut für Strömungsforschung, Göttingen, Germany \\ Z. Naturforsch. 45 a, $1151-1157$ (1990); received June 18, 1990 \\ Proton transfer between ions of the cyclic peptide valinomycin (relative molecular mass 1110.6) \\ and ammonia molecules has been studied over a range of ion energies from $50 \mathrm{eV}$ to $8 \mathrm{keV}$. \\ Valinomycin ions were produced by field desorption. Collisions of valinomycin ions with ammonia \\ molecules at controlled energies were carried out using an ion-optical lens system situated in the \\ source region of a large research mass spectrometer. The maximum cross-section for proton transfer \\ occurred when the valinomycin ion possessed $1500 \mathrm{eV}$ of kinetic energy. This maximum cross-sec- \\ tion for proton transfer was 3 orders of magnitude smaller than the cross-section for collision-in- \\ duced dissociation of the valinomycin ion at the same ion energy $\left(2.4 \cdot 10^{-17} \mathrm{~cm}^{2}\right.$ molecule ${ }^{-1}$ as \\ compared to $2 \cdot 10^{-14} \mathrm{~cm}^{2}$ molecule ${ }^{-1}$ ). A stereospecific stripping model can explain the observa- \\ tions.
}

\section{Introduction}

The enormous body of literature on the subject of ion-molecule reactions concerns almost exclusively ions of relatively low masses [1]. We report results from a study of proton transfer between a beam of peptide ions and ammonia. While a recent study of such reactions concentrated on the regime of very low collision energies [2] the present work extends to higher energies, where different reaction mechanisms apply. Results are presented for the cyclic peptide valinomycin (Fig. 1) with a relative molecular mass of 1110.6. The unimolecular chemistry of gaseous valinomycin ions had been characterised prior to this work [3]. There is a fundamental interest in studying the competition between proton transfer and collision-induced dissociation with large ions. Also, the potential of ion-molecule reactions for obtaining structural information on large biological ions in the gas phase needs to be explored. In general, information of this type is required to assist with the interpretation of tandem mass spectra of biological molecules [4]. A

Reprint requests to Prof. P. J. Derrick, Warwick Institute for Mass Spectrometry, University of Warwick, Coventry CV4 7AL/U.K. special feature of collisions between beams of large ions and thermal small molecules is the possibility of attaining low absolute centre-of-mass collision energies. The maximum proportion of the translational energy of the ion which is available for conversion into integral energy in the collision is given by $m /(M+m)$, where $M$ is the mass of the parent ion and $m$ is the mass of a stationary target molecule. This fraction will be small when the mass of the parent ion is large and the mass of the target is small. In this work ion translational energies from $\sim 50 \mathrm{eV}$ upwards were used, which corresponds to relative collision energies in the case of valinomycin and ammonia of $\geqq 750 \mathrm{meV}$.

\section{Experimental}

The apparatus [Fig. 2] used in this work has been described in detail [5]. Valinomycin ions were produced by field desorption (FD). Collisions of these ions with ammonia molecules were carried out without prior mass-selection. The electrostatic lens system designed for these experiments [5] collected the beam from the FD source and focussed it into a collision cell containing the ammonia molecules. The energy pos- 


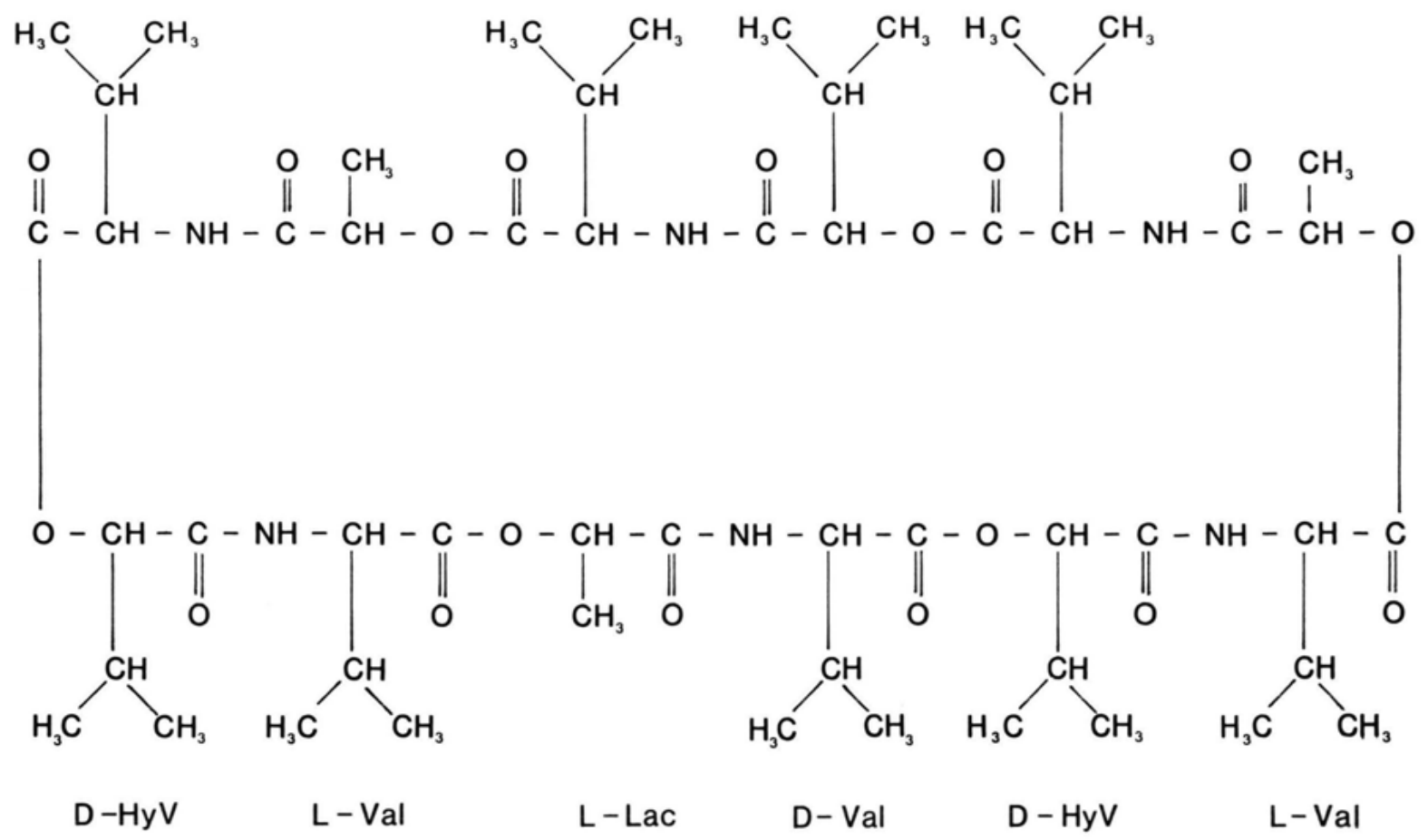

Fig. 1. Valinomycin.

sessed by the ions prior to collision was varied by adjusting the collision cell potential. Product ions were extracted, accelerated and focussed onto the source slit of the mass spectrometer. The performance of the retardation lens/collision cell/acceleration lens system was evaluated by studying the well characterised reactions between $\left[\mathrm{NH}_{3}\right]^{+\cdot}$ and $\mathrm{NH}_{3}[6-13]$. The primary reactions occuring between $\left[\mathrm{NH}_{3}\right]^{+*}$ and $\mathrm{NH}_{3}$ are

and

$$
\left[\mathrm{NH}_{3}\right]^{+\cdot}+\mathrm{NH}_{3} \rightarrow \mathrm{NH}_{2}+\left[\mathrm{NH}_{4}\right]^{+}
$$

$$
\left[\mathrm{NH}_{3}\right]^{+\cdot}+\mathrm{NH}_{3} \rightarrow \mathrm{NH}_{3}+\left[\mathrm{NH}_{3}\right]^{+\cdot}
$$

The rate of the proton transfer reaction is known to decrease with increasing ion kinetic energy, whilst the rate for the electron transfer reaction increases over the range of interest [3]. Uncorrected cross-sections for formation of $\left[\mathrm{NH}_{3}\right]^{+\cdot}$ and $\left[\mathrm{NH}_{4}\right]^{+}$from these two reactions were determined as a function of incident $\left[\mathrm{NH}_{3}\right]^{+\cdot}$ energy, and from comparison with literature data were used to draw up a correction curve accounting for the transmission characteristics of the lens systems and mass spectrometer.

An initial difficulty in the valinomycin experiments was interference from $\left[\mathrm{NH}_{3}\right]^{+\cdot}$ generated in the FD source from a background pressure of $\mathrm{NH}_{3}$. The problem was alleviated by using $\mathrm{ND}_{3}$ instead of $\mathrm{NH}_{3}$. In this case, $\left[\mathrm{ND}_{4}\right]^{+}$wil be formed from $\left[\mathrm{ND}_{3}\right]^{+}$, whereas $\left[\mathrm{ND}_{3} \mathrm{H}\right]^{+}$will be formed by proton transfer from valinomyin ions. The yield of $\left[\mathrm{ND}_{3} \mathrm{H}\right]^{+}$from the collision well was monitored using ion counting techniques [5].

\section{Results}

Field desorption of valinomycin yields primarily molecular ions and no low-mass ions of significant intensity. The molecular ion region of the field desorption spectrum of valinomycin is shown in Figure 3. The spectrum shows peaks due to $[\mathrm{M}]^{+},[\mathrm{M}+\mathrm{H}]^{+}$, $[\mathrm{M}+\mathrm{Na}]^{+}$and $[\mathrm{M}+\mathrm{K}]^{+}$, where $\mathrm{M}$ represents a valinomycin molecule. There are other groups of peaks in the spectrum, which are 14 mass units apart from the group around $m / z$ 1111. The proportion of $[\mathrm{M}]^{+\cdot}$ to $[\mathrm{M}+\mathrm{H}]^{+}$can be obtained if one takes into account the calculated isotope distribution. It was found that these ions were present in about equal proportion.

The collision cell pressure of $\mathrm{ND}_{3}$ was $1.3 \cdot 10^{3}$ torr. Pressures in the cell were calculated from the pressure 


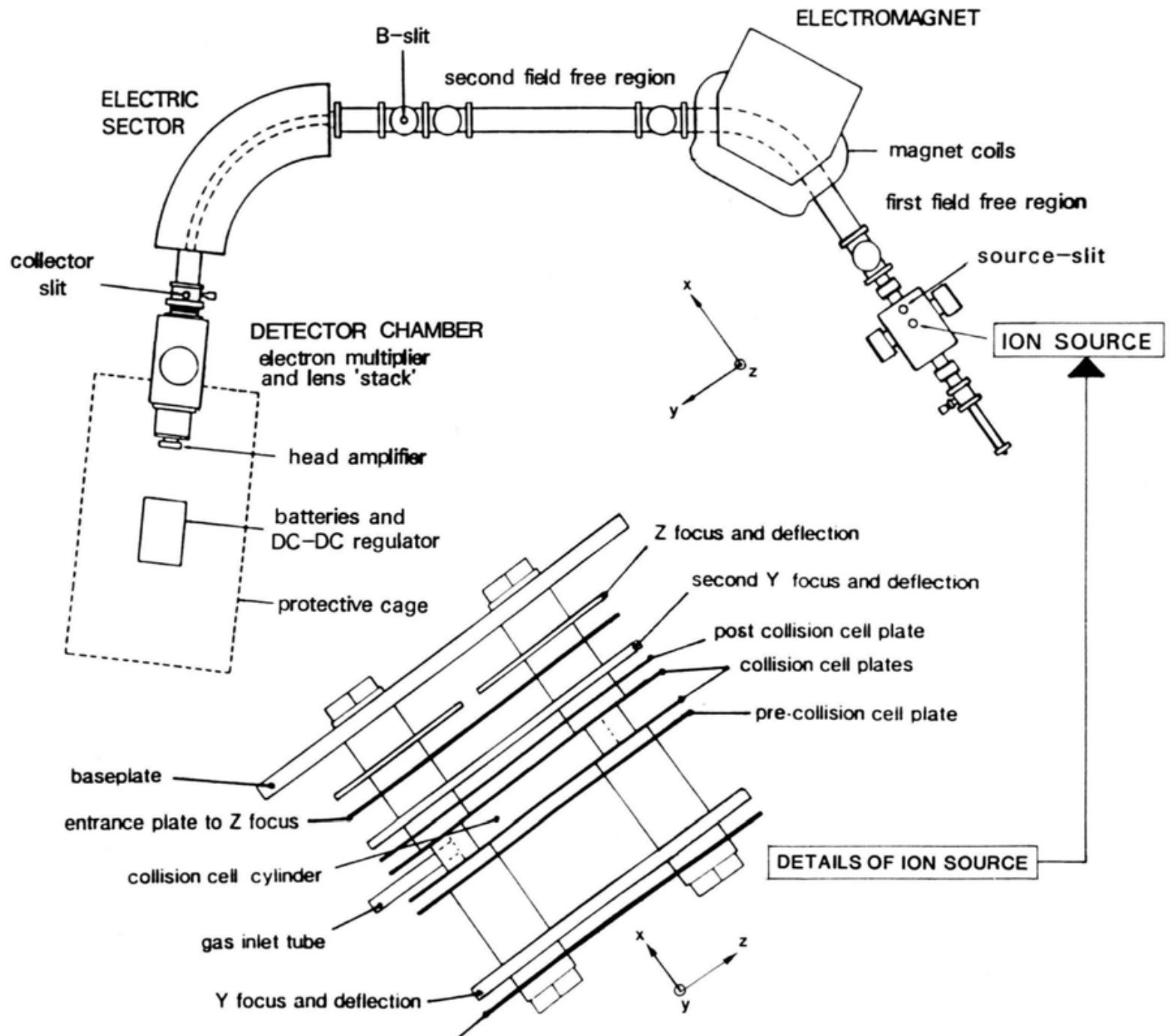

counter electrode for FD

Fig. 2. The collision cell, lenses and mass spectrometer.

measured in the surrounding housing, making correction for the sensitivity of the ionisation gauge to different gases. These calculations were made using the pumping speed of the diffusion pump on the surrounding housing and the conductances of the slits in the cell. The effective length of the interaction region was taken to be $12 \mathrm{~mm}$, which is the distance between the outside walls of the cell. Uncertainties arising from the calculation of the pressure and the effective length used are discussed below.

Results are shown in Figure 4. Incident ion energy and collision cell voltage are plotted on the abscissa. The proportion of $\left[\mathrm{ND}_{3} \mathrm{H}\right]^{+}$relative to the $[\mathrm{M}+\mathrm{H}]^{+}$ signal of valinomycin is plotted on the ordinate. Figure 4 has been drawn up on the assumption that the proton transfer arose from the $[\mathrm{M}+\mathrm{H}]^{+}$ion. The $[\mathrm{M}+\mathrm{H}]^{+}$ion signals used in this calculation of the proportions were corrected for attenuation at this particular cell pressure. The level of $\left[\mathrm{ND}_{3} \mathrm{H}\right]^{+}$signals from the collision cell, when the emitter heating current in the FD source was turned off, was used as a measure of background interference from other reactions. These ions counts were subtracted from the corresponding ion counts measured with the emitter heating current on. The resulting differences in counts were taken as a measure of $\left[\mathrm{ND}_{3} \mathrm{H}\right]^{+}$arising from 


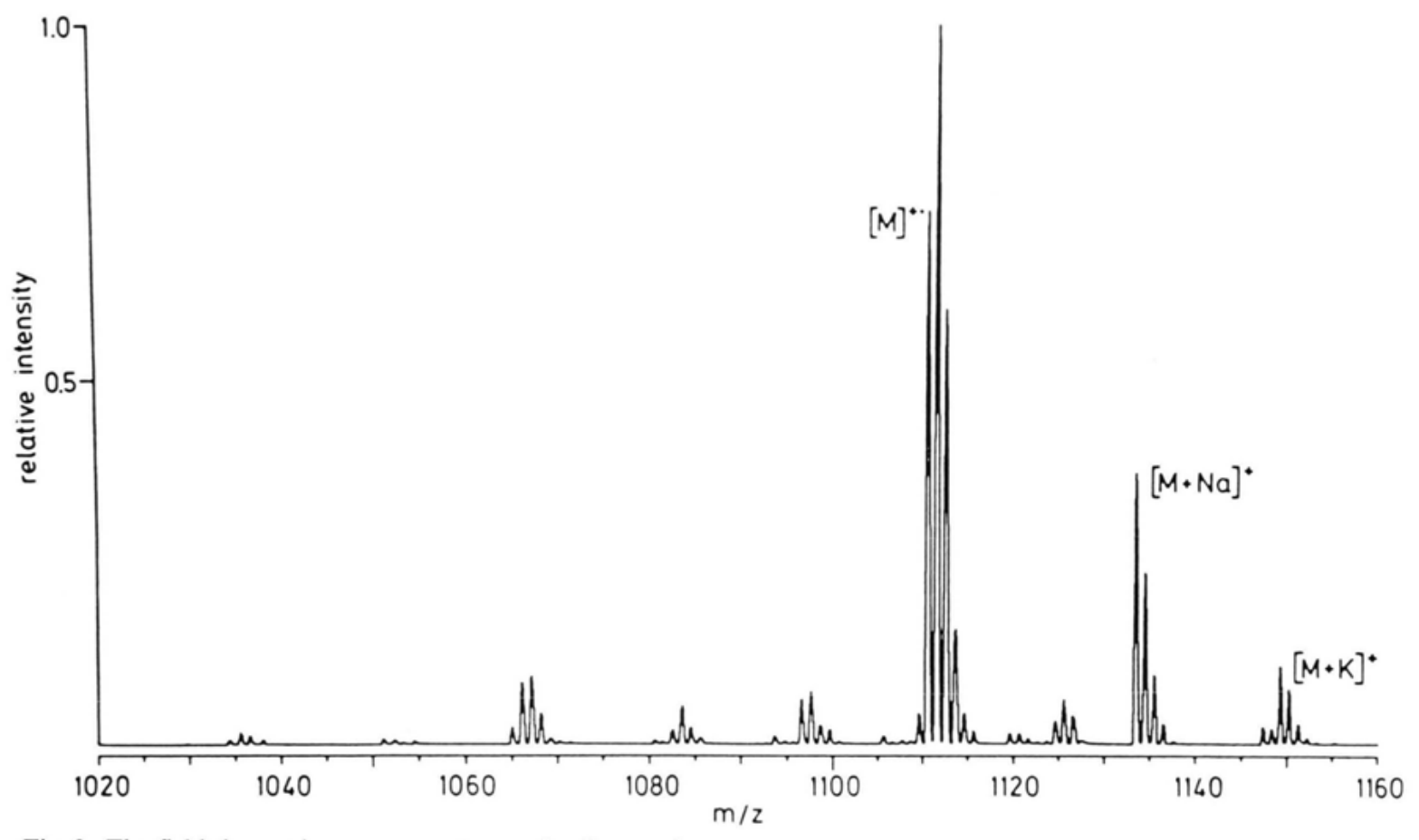

Fig. 3. The field desorption mass spectrum of valinomycin.

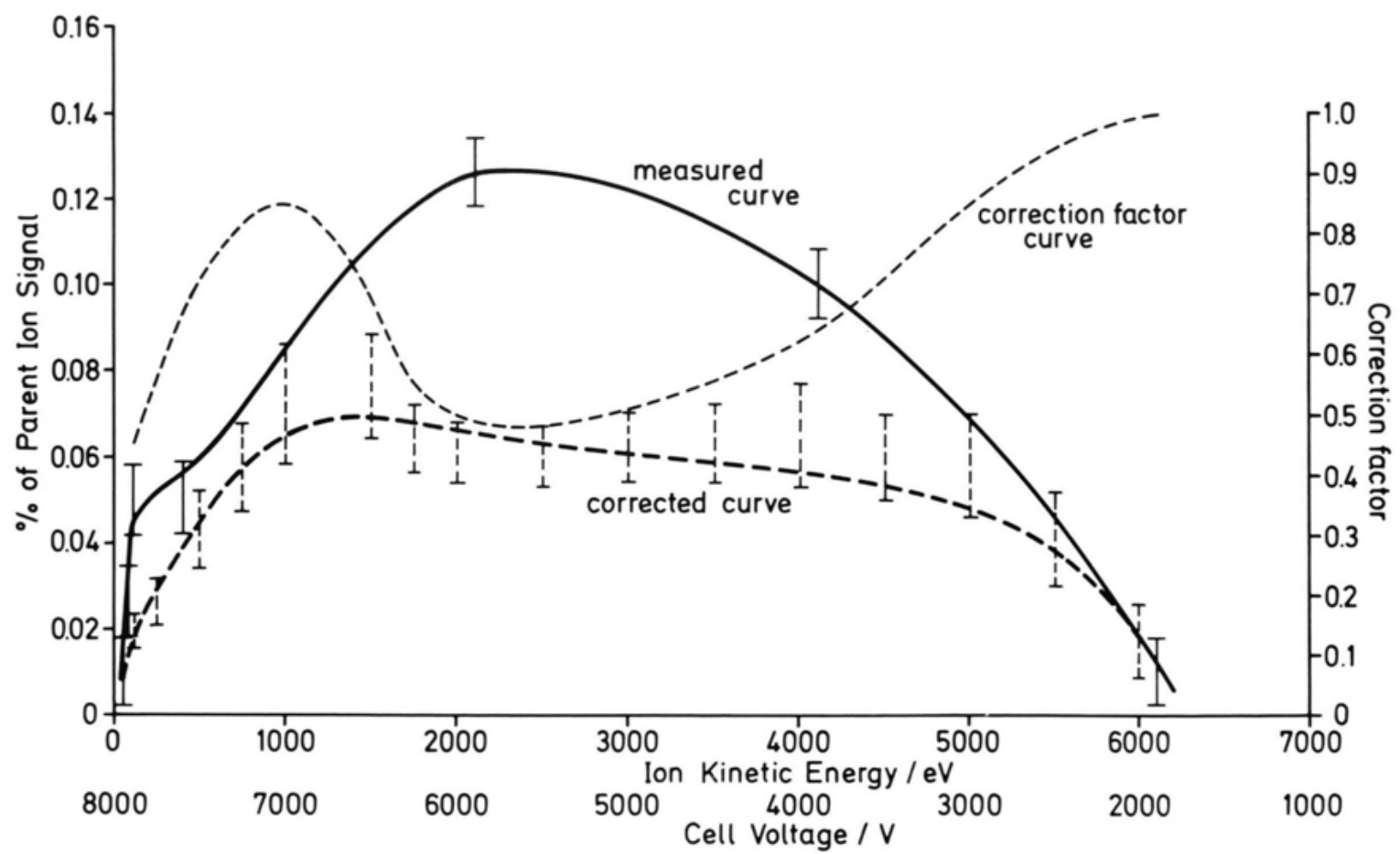

Fig. 4. Yield of $\left[\mathrm{ND}_{3} \mathrm{H}\right]^{+}$as proportion of parent ion signal, as a function of the kinetic energy of the incident valinomycin ions. Error bars of the raw data ("measured curve") are given at a few typical energies. 
valinomycin ions. On average, the background counts were at about the $10 \%$ level. Typical $\left[\mathrm{ND}_{3} \mathrm{H}\right]^{+}$ion signals from the collision cell were less than 10 counts per second. These signals were accumulated for several one-minute periods to obtain an average number of ions/second.

The correction curve, obtained as described in the "Experimental" section, is also given in Figure 4. Its shape is explicable in terms of ion-optical effects [5]. The measured product ions are shown in Fig. 4 as proportions of the transmitted parent ion beam, whereas the amounts of product ions actually formed will be related to the number of parent ions entering the collision cell, not all of which are transmitted through the complete lens system.

There is a maximum (corrected) yield of $\left[\mathrm{ND}_{3} \mathrm{H}\right]^{+}$ of $0.007 \pm 0.00015$ at an ion kinetic energy of about $1500 \mathrm{eV}$ (cell voltage $6500 \mathrm{~V}$ ) (Figure 4). Further corrections are necessary: the proportion of product ions calculated to be extracted through the entrance slit of the collision cell (i.e. in the negative $x$-direction) under the voltage conditions used on the lens system at this cell voltage is 0.30 . This figure is based on calculation of the electric field penetration into the collision cell [4]. Taking this into account gives a maximum $\left[\mathrm{ND}_{3} \mathrm{H}\right]^{+}$yield of $0.0010 \pm 0.0002$. Another point which needs consideration is how much of the $\left[\mathrm{ND}_{3} \mathrm{H}\right]^{+}$product has reacted to produce some other species in the time taken for extraction out of the collision cell. The rate constant for the reaction $\left[\mathrm{ND}_{3} \mathrm{H}\right]^{+}+\mathrm{ND}_{3} \rightarrow\left[\mathrm{ND}_{4}\right]^{+}+\mathrm{NHD}_{2}$ is $1 \cdot 10^{-9} \mathrm{~cm}^{3}$ molecule ${ }^{-1} \mathrm{~s}^{-1}$ [14]. This happens to be the same as the rate constant for the reaction $\left[\mathrm{NH}_{3}\right]^{+\cdot}+\mathrm{NH}_{3} \rightarrow$ $\left[\mathrm{NH}_{4}\right]^{+}+\mathrm{NH}_{2}$ [14]. Since extraction fields very similar to those used in the $\left[\mathrm{NH}_{3}\right]^{+\cdot} / \mathrm{NH}_{3}$ experiments were used in the experiments with valinomycin, it may be assumed that the time for secondary reaction of the products is approximately the same. In the $\left[\mathrm{NH}_{3}\right]^{+\cdot} / \mathrm{NH}_{3}$ experiments, it was found that $0.42 \pm 0.05$ of the $\left[\mathrm{NH}_{3}\right]^{+\cdot}$ had reacted to form $\left[\mathrm{NH}_{4}\right]$ during extraction from the cell. In the measurements of the valinomycin ion/ $\mathrm{ND}_{3}$ reaction the pressure in the collision cell was less (about one-half) than that used in the $\left[\mathrm{NH}_{3}\right]^{+\cdot} / \mathrm{NH}_{3}$ experiments. It can then be calculated [5] that $0.24 \pm 0.03$ of the $\left[\mathrm{ND}_{3} \mathrm{H}\right]^{+}$would have reacted to form $\left[\mathrm{ND}_{4}\right]^{+}$. Allowing for this loss, the estimated maximum yield of $\left[\mathrm{ND}_{3} \mathrm{H}^{+}\right]$becomes $0.0013 \pm 0.0003$. The cross-section for proton transfer from valinomycin to ammonia calculated using this value is $2.4 \cdot 10^{-17} \mathrm{~cm}^{2}$ molecule ${ }^{-1}$.
It is possible to perform a check on the corrections made in obtaining this result. The cross-section for the $\left[\mathrm{NH}_{3}\right]^{+\cdot}+\mathrm{NH}_{3} \rightarrow\left[\mathrm{NH}_{4}\right]^{+}+\mathrm{NH}_{2}$ at an incident ion energy of $100 \mathrm{eV}$ was determined in our experiments to be $4.9 \cdot 10^{-15} \mathrm{~cm}^{2}$ molecule ${ }^{-1}$ without adjustment. This is $3 \times$ lower than the literature value [7]. The adjustments to account for ion losses as described in the previous paragraph raise cross-sections by a factor of $(1+0.3) /(1-0.24)=1.71$, which suggest that the corrections made may still be too small by almost a factor of 2. This may be attributable to the value $(12 \mathrm{~mm})$ used for the interaction length. We estimate the uncertainty in the cross-sections at $50 \%$, so that the cross-section for proton transfer from valinomycin to ammonia is $2.4 \pm 1.2 \cdot 10^{-17} \mathrm{~cm}^{2}$ molecule ${ }^{-1}$.

It has been assumed that the proton transfer observed is due to the $[\mathrm{M}+\mathrm{H}]^{+}$ion of valinomycin. The possibility cannot be excluded that transfer also occurs from the $[\mathrm{M}]^{+\cdot}$ ion of valinomycin. Since $[\mathrm{M}+\mathrm{H}]^{+\cdot}$ and $[\mathrm{M}]^{+\cdot}$ are produced in about equal intensities, the experimental cross-section would then represent an average of the cross-sections for these ions.

At the $\mathrm{ND}_{3}$ pressure used in the collision cell in the valinomycin experiments, the transmitted beam was attenuated to $33 \%$ (above about $400 \mathrm{eV}$ ion kinetic energy). If it were assumed that all $67 \%$ of the $[\mathrm{M}+\mathrm{H}]^{+}$ions lost had undergone collision-induced decomposition (CID), the calculated cross-section for CID would be $2.0 \cdot 10^{-14} \mathrm{~cm}^{2}$ molecule ${ }^{-1}$, about three orders of magnitude larger than the cross section for proton transfer. This can easily be understood. In order for proton transfer to occur, the $\mathrm{ND}_{3}$ molecule would have to interact with a specific part of the $[\mathrm{M}+\mathrm{H}]^{+}$valinomycin ion where the additional proton was situated. CID, on the other hand, could result from interaction with many other parts of the ion structure. Proton transfer from fragment ions formed in the dominant CID process has been ignored, on the grounds that the probability of CID followed by proton transfer is likely to be low. The possibility exists, however, that some of the proton transfer events are accompanied by a simultaneous break-up of the remainder of the valinomycin ion - i.e. proton transfer and CID need not be mutually exclusive.

\section{Discussion}

The principal findings of this work are the unusual energy dependence of the cross section for proton 
transfer from a valinomycin ion to $\mathrm{ND}_{3}$ and its very small absolute size. From Fig. 4, the cross section goes through a broad maximum of $2.4 \cdot 10^{17} \mathrm{~cm}^{2}$ at $1500 \mathrm{eV}$, corresponding to $26.5 \mathrm{eV}$ in the centre-of-mass system. A comparison with the formation of $\left[\mathrm{NH}_{4}\right]^{+}$ from $\left[\mathrm{NH}_{3}\right]^{+\cdot}+\mathrm{NH}_{3}$ is interesting. Here, the cross section has its maximum at room temperature thermal energy, where it is $1.16 \cdot 10^{-14} \mathrm{~cm}^{2}$ (calculated from the rate constant). At $1 \mathrm{eV}$ ion energy this cross section is lower by a factor of about 0.85 and continues to decrease towards higher energies. At $100 \mathrm{eV}$, corresponding to $50 \mathrm{eV}_{\mathrm{CM}}$, a value of $8.4 \pm 4.2 \cdot 10^{-15}$ $\mathrm{cm}^{2}$ was measured in this work (after correction with the loss factor of 1.71 , see above). Thus at comparable relative collision energies (within a factor of two), the valinomycin ion cross section is smaller by several orders of magnitude than that of $\left[\mathrm{NH}_{3}\right]^{+*}$; furthermore, at low energies it shows a pronounced increase with kinetic energy.

For both reactions, at very low collision energies formation of an orbiting complex would be expected. According to the Langevin cross section expression, the capture probability depends only on the relative collision energy $E_{\mathrm{CM}}$ and the target polarizability and would thus be the same for a valinomycin ion $+\mathrm{ND}_{3}$ and for $\left[\mathrm{NH}_{3}\right]^{+\cdot}+\mathrm{NH}_{3}$ at a given $\mathrm{CM}$ energy. Complex formation has, in fact, been observed for protonated valinomycin ions plus $\mathrm{NH}_{3}$ at $E_{\mathrm{CM}} \leqq 0.5 \mathrm{eV}$ [2]. The probability for the orbiting mechanism decreases as $\left(E_{\mathrm{CM}}\right)^{-1 / 2}$ and is usually found to become insignificant, compared to other mechanisms, above a few $\mathrm{eV}_{\mathrm{CM}}$.

A very successful model for reactions at higher energies is the spectator stripping mechanism. Applying this model to the case of proton transfer from a protonated valinomycin ion $[\mathrm{M}+\mathrm{H}]^{+}$colliding with a stationary $\mathrm{ND}_{3}$ molecule, one finds that the fraction of the initial lab system kinetic energy which is deposited in the $\left[\mathrm{ND}_{3} \mathrm{H}\right]^{+}$product equals $\mu /(M+1) . \mu=0.952$ is the reduced mass of the $\mathrm{ND}_{3}$-proton subsystem, and $M=1111$. Thus out of the initial energy $E_{\mathrm{lab}}=1500 \mathrm{eV}$, only $1.29 \mathrm{eV}$ is available in the $\mathrm{ND}_{3}$-proton relative motion. This small amount of energy may well be comparable with some energy barrier along the reaction path, which would inhibit this proton transfer mechanism at lower energies. We propose therefore a stripping mechanism, in conjunction with a small barrier, to explain the observed, unusual rise of the cross section up to a $\mathrm{CM}$ energy of $26.5 \mathrm{eV}$ (which contrasts with the much more typical, monotonic fall-off for
$\left[\mathrm{NH}_{3}\right]^{+\cdot}+\mathrm{NH}_{3}$ in the same energy region). The proton transfer from valinomycin is certainly not a strongly endothermic reaction [2], and the increase of the cross section cannot be explained simply on the basis of the overall energy balance.

The small size of the measured cross section is also in keeping with the spectator stripping model. Viewed in the centre-of-mass system, the reaction proceeds by the impact of the $\mathrm{ND}_{3}$ molecule onto the almost stationary valinomycin ion. It is intuitively clear that the proton can only be stripped off if it is hit directly. Thus stereospecific factors such as shielding effects from other parts of the ion structure will tend to reduce the cross section. Two types of protonation sites of valinomycin, at the ester oxygen and at the amide bond, have in fact been distinguished in [2]. By comparison, in the $\left[\mathrm{NH}_{3}\right]^{+\cdot}+\mathrm{NH}_{3}$ case such steric requirements are absent.

The interaction time between $\mathrm{ND}_{3}$ and the proton, at $E_{\text {lab }}=1500 \mathrm{eV}$, can be estimated as $1.8 \cdot 10^{-14} \mathrm{sec}$ (taking the $\mathrm{ND}_{3}$ diameter as $3 \AA$ ). This is small compared to the period of rotation of the valinomycin ion, which is a measure of the time which would be necessary to sample a range of different orientations. Thus the prerequisite for a spectator-type sudden collision with a target of fixed orientation is fulfilled.

It many be noted that the comparison with the absolute $\left[\mathrm{NH}_{3}\right]^{+\cdot}+\mathrm{NH}_{3}$ cross section is further complicated by the fact that in the latter case $\left[\mathrm{NH}_{4}\right]^{+}$can also be formed by transfer of a hydrogen atom from $\mathrm{NH}_{3}$ to $\left[\mathrm{NH}_{3}\right]^{+\cdot}$, in addition to the proton transfer mechanism implicitly assumed above. The product thus formed would be fast in the laboratory-system forward direction and might in fact be detected with a higher probability than the slow $\left[\mathrm{NH}_{4}\right]^{+}$resulting from proton transfer. In the similar system $\left[\mathrm{CH}_{4}\right]^{+\cdot}+\mathrm{CH}_{4} \rightarrow\left[\mathrm{CH}_{5}\right]^{+}+\mathrm{CH}_{3}$ both mechanisms have been observed with comparable probability [15], while with $\left[\mathrm{D}_{2} \mathrm{O}\right]^{+\cdot}+\mathrm{NH}_{3}$ only atom transfer was found, and no formation of $\left[\mathrm{NH}_{3} \mathrm{D}\right]^{+}$at all $[15,16]$.

\section{Conclusion}

The result for proton transfer from valinomycin to ammonia suggest that the cross-section for such ionmolecule reactions between large ions and small molecules are very small. A clean interaction at the position necessary for the proton transfer is apparently required, otherwise the ion will tend to fragment. The centre-off-mass collision energy giving the maxi- 
mum cross-section for proton transfer to ammonia has been found to be much greater for valinomycin ions than that for ammonia ions. The amount of this collision energy actually converted into internal energy of the product ion would be expected to depend on whether reaction occurs at a specific localized site or with larger parts of the structure of the ion as a whole. In the case of valinomycin the interaction time is very short, favouring the former alternative.

[1] (a) J. L. Franklin, ed., Ion-Molecule Reaction, Plenum Press, New York 1972.

(b) M. T. Bowers, ed., Gas Phase Ion Chemistry, Academic Press, New York 1979.

[2] R. Orlando, C. Fenselau, and R. J. Cotter, Org. Mass Spectrom. 241033 (1989).

[3] M. M. Sheil, Ph.D. Thesis, University of New South Wales, Australia (1987).

[4] F. W. McLafferty, ed., Tandem Mass Spectrometry, Wiley, Chichester.

[5] S. C. Davis, Ph.D. Thesis, University of New South Wales, Australia (1988).

[6] L. M. Dortman and P. C. Noble, J. Amer. Chem. Soc. 63, 980 (1959).

[7] G. A. W. Derwish, A. Galli, A. Giardini-Guidoni, and G. G. Volpi, J. Chem. Phys. 39, 1599 (1963).

\section{Acknowledgements}

All measurements were made in the School of Chemistry, University of New South Wales, Australia. We are pleased to acknowledge financial support under the Australian Research Grants Scheme. We thank Prof. Z. Herman for a discussion on his unpublished results.

[8] M. S. B. Munson, J. Phys. Chem. 70, 2034 (1966).

[9] A. G. Harrison and J. C. J. Thynne, Trans. Faraday Soc. 62, 2804 (1966).

[10] S. K. Gupta, E. G. Jones, A. G. Harrison, and J. J. Myher, Can. J. Chem. 45, 3107 (1967).

[11] C. E. Melton, J. Chem. Phys. 45, 4414 (1966).

[12] W. A. Chupka and M. E. Russell, J. Chem. Phys. 48, 1527 (1968).

[13] W. T. Huntress Jr., M. M. Moseman, and D. D. Elleman, J. Chem. Phys. 54, 843 (1971).

[14] T. B. McMahon, P. G. Miasek, and J. L. Beauchamp, Int. J. Mass Spectrom. Ion Phys. 21, 63 (1979).

[15] Z. Herman (priv. comm.).

[16] J. Vancura and Z. Herman, Coll. Czechoslovak Chem. Commun 53, 2168 (1988). 